\title{
A Prospective Population Pharmacokinetic Study on Morphine Metabolism in Cancer Patients
}

\author{
Astrid W. Oosten ${ }^{1} \cdot$ João A. Abrantes ${ }^{2} \cdot$ Siv Jönsson ${ }^{2}$ Maja Matic ${ }^{3,4}$. \\ Ron H. N. van Schaik ${ }^{3}$ Peter de Bruijn ${ }^{1}$ Carin C. D. van der Rijt ${ }^{1,5}$. \\ Ron H. J. Mathijssen ${ }^{1}$
}

Published online: 5 November 2016

(c) The Author(s) 2016. This article is published with open access at Springerlink.com

\begin{abstract}
Background Oral and subcutaneous morphine is widely used for the treatment of cancer-related pain; however, solid pharmacokinetic data on this practice are lacking. Furthermore, it is largely unknown which factors contribute to the variability in clearances of morphine and its metabolites and whether morphine clearance is related to treatment outcome.

Methods Blood samples from 49 cancer patients treated with oral and/or subcutaneous morphine were prospectively collected and were used to develop a population pharmacokinetic model for morphine, morphine-3-glucuronide (M3G) and morphine-6-glucuronide (M6G). The
\end{abstract}

A. W. Oosten and J. A. Abrantes contributed equally to this work.

Electronic supplementary material The online version of this article (doi:10.1007/s40262-016-0471-7) contains supplementary material, which is available to authorized users.

Astrid W. Oosten

a.oosten@erasmusmc.nl

1 Department of Medical Oncology, Erasmus MC Cancer Institute, Groene Hilledijk 301, 3075 EA Rotterdam, The Netherlands

2 Department of Pharmaceutical Biosciences, Uppsala University, Uppsala, Sweden

3 Department of Clinical Chemistry, Erasmus MC, Rotterdam, The Netherlands

4 Department of Pediatric Surgery, Erasmus MC, Sophia Children's Hospital, Rotterdam, The Netherlands

5 Netherlands Comprehensive Cancer Organisation, Utrecht, The Netherlands influence of age, gender, renal function and several polymorphisms possibly related to the pharmacokinetics of the three compounds was investigated. In addition, the relation between treatment failure and morphine and metabolite clearances was explored.

Results A one-compartment model including an extensive first-pass effect adequately described the data of morphine and its metabolites. Estimated mean area under the plasma concentration-time curve (AUC) ratios following oral versus subcutaneous administration were: $\mathrm{M} 3 \mathrm{G} / \mathrm{morphine}$ 29.7:1 vs. 11.1:1; M6G/morphine 5.26:1 vs. 1.95:1; and M3G/M6G 5.65:1 vs. 5.70:1. Renal function was significantly correlated with clearance of the metabolites, which increased $0.602 \mathrm{~L} / \mathrm{h}$ per every $10 \mathrm{~mL} / \mathrm{min} / 1.73 \mathrm{~m}^{2}$ increase of estimated glomerular filtration rate (eGFR), reaching a plateau for eGFR $>90 \mathrm{~mL} / \mathrm{min} / 1.73 \mathrm{~m}^{2}$. The clearance of morphine or its metabolites was not found to be correlated with treatment failure.

Conclusion The influence of age-, gender- and pharmacokinetic-related polymorphisms was not identified on the pharmacokinetics of morphine. Clearance of morphine or its metabolites was not found to explain treatment outcome; however, large variations in plasma concentrations of morphine, M3G and M6G support further studies on the relation between plasma concentrations and treatment outcome.

Dutch Trial Register ID: NTR4369. 


\section{Key Points}

We describe the pharmacokinetics of morphine, morphine-3-glucuronide (M3G) and morphine-6glucuronide (M6G) after subcutaneous and oral administration in cancer patients, including firstorder systemic and additional first-pass formation from morphine for the metabolites.

Variations in area under the plasma concentrationtime curve (AUC) ratios of M3G:morphine and M6G:morphine related to first-pass effect and renal function support further studies on the relation between plasma concentrations and treatment outcome.

We did not identify significant effects of age, gender and polymorphisms in $U G T 2 B 7, S L C 22 A I$ and $A B C C 3$ on total clearance of morphine and morphine metabolic clearances to M3G or M6G. Furthermore, failure of treatment could not be related to the clearance of morphine or its metabolites.

\section{Introduction}

Morphine is a widely used opioid analgesic and is one of the preferred treatment options for the treatment of cancerrelated pain [1].

After intravenous administration, morphine is rapidly distributed from the central compartment to highly perfused tissues (distribution half-life $\left[t_{1 / 2}\right]=0.9-2.5 \mathrm{~min}$ ), and thereafter the plasma concentrations versus time decay in a biphasic way, with a short mean terminal elimination $t_{1 / 2}$ of 1.4-3.4 h that is similar for intravenous, subcutaneous and oral administrations [2,3]. After oral administration, morphine undergoes extensive hepatic first-pass metabolism [2, 3], and is predominantly metabolized through glucuronidation in the liver into the conjugates morphine-3-glucuronide (M3G; 45-55\%) and morphine-6glucuronide (M6G; 10-15\%) [4-6]. While M6G is thought to contribute to the analgesic effects [7-9], the effects of M3G are unclear. It has been associated with (central) side effects and the development of tolerance to the analgesic effects in rats $[10,11]$, but direct administration to humans did not produce any clinical effects [12].

Morphine is available for different routes of administration. For fast titration in cases of severe pain, we mainly use continuous subcutaneous administration. This has been found to be safe and effective [13, 14], has advantages over the intravenous route, and can also be applied safely in an out-of-hospital setting $[13,15]$.

Little is known about the pharmacokinetics of morphine after continuous subcutaneous administration in cancer patients, and solid pharmacokinetic data after oral administration are also lacking. Furthermore, while substantial inter- and intraindividual variability in plasma concentrations of morphine, M3G and M6G has been reported after oral as well as subcutaneous administration [16, 17], the causes for this variability and its effects on clinical outcomes of treatment are incompletely understood. Although treatment with morphine is unsuccessful in approximately $30 \%$ of patients [18], it is unknown what causes these treatment failures. A number of clinical factors such as age and gender, as well as genetic factors, have been associated with variability in pharmacokinetics and/or dynamics of morphine [19-22] but data are sparse and to date only a small part of variability can be explained at best.

The objectives of the current population pharmacokinetic analysis were to describe the pharmacokinetics and metabolic ratios of morphine, M3G and M6G following subcutaneous and oral administration of morphine. As a second objective, the influence of age, gender, renal function and polymorphisms in several pharmacokineticrelated genes on the pharmacokinetics of morphine, M3G and M6G was investigated. Finally, the relation between outcome of treatment and the clearance of morphine and its metabolites was explored.

\section{Patients, Materials and Methods}

Between February 2010 and March 2014, patients admitted to the Erasmus MC Cancer Institute (Rotterdam, The Netherlands) and treated with morphine for moderate to severe cancer-related nociceptive pain were asked to participate in the study. All patients treated with morphine were eligible, i.e. patients already treated with morphine before admission but also opioid-naive patients or patients rotating to morphine after failure of treatment with another type of opioid. Morphine was available as hydrochloride-3water (molecular weight $375.84 \mathrm{mg} / \mathrm{mmol}$ ) $10 \mathrm{mg} / \mathrm{mL}$ for parenteral administration and as 5-sulphate-water (molecular weight $758.83 \mathrm{mg} / \mathrm{mmol}$ ) extended-release (ER; tablet $10,20,60,100 \mathrm{mg}$ ) and immediate-release (IR) formulation (liquid $20 \mathrm{mg} / \mathrm{mL}$ or dose unit $10,30 \mathrm{mg}$ ) for oral administration. The starting dose in opioid-naive patients is usually $10 \mathrm{mg}$ twice daily or $1 \mathrm{mg} / \mathrm{h}$ parenterally, depending on the clinical circumstances. Doses in nonnaive patients are based on previous treatments. Patients treated with a fentanyl patch who were prescribed IR oral morphine for treatment of breakthrough pain could also be included in the study. In cases of severe pain, patients were 
titrated by continuous subcutaneous infusion, with the possibility of an extra bolus every hour. Doses were titrated based on clinical effects. When pain control was reached and doses were stabilized, patients could be rotated to oral ER morphine, with IR morphine prescribed as needed, using a 1:3 dose conversion ratio [23]. Gender, age and weight $(\mathrm{kg})$ at study entry were recorded, as well as baseline creatinine values $(\mu \mathrm{mol} / \mathrm{L})$. The Modification of Diet in Renal Disease (MDRD) formula was used to calculate the glomerular filtration rates for all patients, and values $>90 \mathrm{~mL} / \mathrm{min} / 1.73 \mathrm{~m}^{2}$ were truncated:

$$
\begin{aligned}
\mathrm{eGFR}\left(\mathrm{mL} / \mathrm{min} / 1.73 \mathrm{~m}^{2}\right)= & 175 \times(0.0113 \\
& \left.\times S_{\mathrm{cr}[\mu \mathrm{mol} / \mathrm{L}]}\right)^{-1.154} \\
& \times \mathrm{age}_{[\mathrm{y}-0.203]}^{-0.23} \\
& \times(0.742 \text { if female }) .
\end{aligned}
$$

For every patient treated with long-acting or continuous morphine, the outcome of treatment was classified as failure or non-failure. The response was classified as failure in cases of rotation to another type of opioid or treatment with intrathecal opioids because of insufficient pain control and/or side effects or the use of palliative sedation because of refractory symptoms associated with opioid treatment in the dying phase.

\subsection{Pharmacokinetic Sample Collection}

Patients were included in the study as soon as possible after hospital admission or after the start of morphine. Blood samples for pharmacokinetic analysis were taken during a maximum of $72 \mathrm{~h}$ after the start of morphine and after each change in the opioid regimen (dose, route of administration). The protocol prescribed sampling twice daily, just before the administration of oral ER morphine or around 8:00 am and 8:00 pm in cases of continuous administration, a baseline sample before every change in the regimen, and a series of samples maximally once daily around the administration of a subcutaneous bolus or oral IR formulation at baseline and 5, 15, 30 and $60 \mathrm{~min}$ after administration. Samples were collected using potassium EDTA tubes. After centrifugation of the tube, the supernatant was collected and stored at $-70{ }^{\circ} \mathrm{C}$ until analysis at the laboratory of Translational Pharmacology (Erasmus MC Cancer Institute).

\subsection{Measurements of Plasma Concentrations of Morphine, Morphine-3-Glucuronide and Morphine-6-Glucuronide}

Morphine and its metabolites in plasma were quantitated using a validated ultra performance liquid chromatography tandem mass spectrometer (UPLC-MS/MS) method consisting of a Waters Acquity UPLC sample manager coupled with a triple quadruple mass spectrometer operating in the multiple reaction monitoring (MRM) mode with positive ion electrospray ionization (Waters, EttenLeur, The Netherlands). The MRM transitions were set at $286 \rightarrow 201$ and $462 \rightarrow 286$ for morphine and M3G and M6G, respectively.

Chromatographic separations for morphine were achieved on an Acquity UPLC $^{\circledR}$ BEH C18 $1.7 \mu \mathrm{m}$ $2.1 \times 100 \mathrm{~mm}$ column eluted at a flow rate of $0.350 \mathrm{~mL} /$ min on a gradient of methanol. The overall cycle time of the method was $6 \mathrm{~min}$. The calibration curves were linear over the range of $1.00-100 \mathrm{ng} / \mathrm{mL}$, with the lower limit of quantitation (LLQ) validated at $1.00 \mathrm{ng} / \mathrm{mL}$ for morphine. The within- and between-run precisions at five tested concentrations, including the LLQ, were $\leq 10.3$ and $\leq 8.67 \%$, respectively, while the average accuracy ranged from 91.9 to $96.9 \%$. The interday coefficient of variation $(\mathrm{CV})$ at five tested concentrations, including the LLQ, was $\leq 11.8 \%$ in individual validation runs. The extraction of $200 \mu \mathrm{L}$ of plasma involved a deproteinization step with acetone, followed by a simple liquid extraction with ethyl acetate. For M3G and M6G, chromatographic separations were achieved on a VisionHT C18-P $3 \mu \mathrm{m} 2.1 \times 50 \mathrm{~mm}$ column eluted at a flow rate of $0.250 \mathrm{~mL} / \mathrm{min}$ on a gradient of acetonitrile. The overall cycle time of the method was $10 \mathrm{~min}$. The calibration curves were linear over the range of $10.0-1000 \mathrm{ng} / \mathrm{mL}$ for $\mathrm{M} 3 \mathrm{G}$ and $2.00-200 \mathrm{ng} / \mathrm{mL}$ for M6G, with the LLQ validated at $10.0 \mathrm{ng} / \mathrm{mL}$ for $\mathrm{M} 3 \mathrm{G}$ and $2.00 \mathrm{ng} / \mathrm{mL}$ for M6G. In patients with metabolite concentrations above these values, samples were adequately diluted in blank human plasma prior to processing until the signal fell within the calibration range. The within- and between-run precisions at five tested concentrations in human potassium EDTA plasma for M3G, including the LLQ, were $\leq 5.16$ and $\leq 2.18 \%$, respectively, while the average accuracy ranged from 84.0 to $96.5 \%$. For M6G, the within- and between-run precisions at five tested concentrations, including the LLQ, were $\leq 16.2$ and $\leq 9.12 \%$, respectively, while the average accuracy ranged from 87.0 to $105.5 \%$. The interday $\mathrm{CV}$ at five tested concentrations, including the LLQ, was $\leq 8.1$ and $\leq 8.2 \%$ for $\mathrm{M} 3 \mathrm{G}$ and M6G, respectively, in individual validation runs. The morphine glucuronides were extracted from $100 \mu \mathrm{L}$ aliquots of plasma after the addition of $850 \mu \mathrm{L}$ ammonium carbonate buffer $\mathrm{pH} 8.8$ followed by a solid-phase extraction using Oasis ${ }^{\circledR}$ HLB $1 \mathrm{cc}(30 \mathrm{mg})$ SPE columns.

\subsection{Single Nucleotide Polymorphism Analysis}

Single nucleotide polymorphisms (SNPs) that have been related to morphine pharmacokinetics were studied (Table 1). DNA was isolated from $1 \mathrm{~mL}$ EDTA blood on the MagNA Pure LC 2.0 instrument (Roche Diagnostics), 
Table 1 Summary of selected genetic variants

UGT2B7

UGT2B7 is a phase II (glucuronidation) metabolizing enzyme encoded by the UGT2B7 gene

UGT2B7 is involved in the conversion of morphine into M3G and M6G

The $\mathrm{G}$ allele of polymorphism $-900 \mathrm{G}>\mathrm{A}$ (rs7438135), which is in complete LD with polymorphism $802 \mathrm{C}>\mathrm{T}$, has been associated with decreased glucuronidation $[56,57]$

SLC22A1

OCT1 is encoded by the $S L C 22 A 1$ gene

OCT1, expressed at the sinusoidal membrane of the human liver, mediates the cellular uptake of morphine [51]

Healthy volunteers with SLC22A1 polymorphisms have reduced morphine uptake in the hepatocytes [54]

Children with two loss-of-function SLC22A1 alleles have lower morphine clearance than carriers of the active SLC22A1 alleles [55]

$\mathrm{ABCC} 3$

$\mathrm{ABCC} 3$ is an organic anion transporter encoded by the $A B C C 3$ gene

$\mathrm{ABCC} 3$, expressed on the basolateral membranes of hepatocytes, mediates the efflux of M3G, and mostly likely also M6G, into the bloodstream [58]

ABCC3 polymorphism $-211 \mathrm{C}>\mathrm{T}$ (rs4793665) was associated with a significantly altered mRNA expression [59, 60]

Children with the $-211 \mathrm{CC}$ genotype had significantly higher M3G and M6G levels (approximately 40\%) than carriers of the $-211 \mathrm{~T}$ allele [55]

$U G T 2 B 7$ uridine $5^{\prime}$-diphospho-glucuronosyltransferase 2B7, $L D$ linkage disequilibrium, $M 3 G$ morphine-3-glucuronide, $M 6 G$ morphine-6-glucuronide, $O C T 1$ organic cation transporter 1, ABCC3 ATP-binding cassette C3, mRNA messenger RNA

with further analysis performed on the 7500 Real-Time PCR System (Life Technologies). Hardy-Weinberg equilibrium was calculated using the Chi-squared test. Additionally, the observed minor allele frequency (MAF) was compared using the European MAF from HapMap in dbSNP (National Center for Biotechnology Information). The SLC22Al haplotype (consisting of either two active alleles, a combination of one active and one inactive allele, or two inactive alleles) was estimated based on the expectation maximization (EM) logarithm with the $R$ (version 3.1.1) haplo.stats package, using a posterior probability $>0.98$.

\subsection{Population Pharmacokinetic Modeling}

The analysis of concentration-time data of morphine and its metabolites was conducted with the first-order conditional estimation method with eta-epsilon interaction through non-linear mixed-effects modeling in NONMEM (version 7.3; Icon Development Solutions, Hanover, MD, USA) [24]. Model building was supported by Perl-speaksNONMEM version 4.2.0, Xpose version 4.4.1 [25], and R version 3.2.0.

Concentration data and doses of morphine were expressed as free base in molar units ( $\mathrm{nmol} / \mathrm{L}$ and $\mathrm{nmol}$, respectively), the latter calculated taking into account the salt administered. All dosing history regarding administration of morphine before and during the period of sampling was included in the dataset. Concentrations below the LLQ comprised 7.6, 0.7 and $0.9 \%$ of the data of morphine, M3G and M6G, respectively, and were discarded from the analysis [26].
First, a pharmacokinetic model was developed for morphine following subcutaneous and oral administration, starting out from previously published models [27, 28]. Oral bioavailability was estimated under the assumption of complete subcutaneous bioavailability, as indicated in the current literature [29-31]. Thereafter, the model was extended to also describe the pharmacokinetics of the metabolites. The rate of appearance of the metabolites was parameterized as a fraction of the rate of elimination of morphine, with fractions fixed to literature values [4-6]. The inclusion of first-pass formation of metabolites following oral morphine was assessed in the model, and the sum of the estimated fractions of morphine reaching the systemic circulation unchanged or undergoing first-pass metabolism to metabolites was constrained to a maximum of 1 . The influence of age and gender on the pharmacokinetic profiles was explored and the relationship between estimated glomerular filtration rate (eGFR) and clearance of the metabolites was assessed.

Interindividual variability (IIV) in pharmacokinetic parameters was modeled using log-normal models. Homoscedastic, heteroscedastic and combined residual error models were evaluated. The correlation between parent drug and metabolite concentrations from the same sample was taken into account utilizing the $\mathrm{L} 2$ data item in NONMEM.

Selection between alternative models was based on scientific plausibility, statistical significance, precision in parameter estimates and visual inspection of goodness-of-fit plots. Statistical significance was determined using the likelihood ratio test with the NONMEM objective function value (OFV). The OFV is given by minus twice the log 
likelihood, and a difference in $\mathrm{OFV}(\triangle \mathrm{OFV})$ between nested models is approximately Chi-square distributed. A $\triangle \mathrm{OFV}$ of 6.64 and 10.8 corresponds to $p$ values of 0.01 and 0.001 , when one parameter is added to the model $(1 d f)$. The reliability of various diagnostic plots was judged based on the magnitude of $\eta$ - and $\varepsilon$-shrinkage [32]. The precision of the model parameter estimates was obtained using the sampling importance resampling (SIR) method [33]. In addition to the general advantages of SIR (e.g. fast run times as it does not require estimation steps, flexibility in addressing asymmetric confidence intervals), SIR was deemed more appropriate than the bootstrap in this case because it is less sensitive to sample size and does not require stratification of the data, which is particularly useful with unbalanced study designs involving a few subjects. Further details on the SIR procedure are presented in electronic supplementary material. The predictive performance of the final model was evaluated using visual predictive checks (VPCs) or population prediction-corrected VPCs (pcVPCs) [34] for the observed concentrations, as well as for concentration ratios. The concentration ratios M3G:M, M6G:M and M3G:M6G, uniquely following the subcutaneous or oral route of administration, were calculated by dividing the respective observed or simulated concentrations.

\subsection{Influence of Genetic Variants and Assessment of Treatment Failure}

After finalization of the population pharmacokinetic model, the influence of UGT2B7 (rs7438135), SLC22A1 (rs72552763, rs12208357, rs34130495, rs34059508) and $A B C C 3$ (rs4793665) genetic variants were explored on total morphine clearance and morphine metabolic clearances to M3G and M6G; $A B C C 3$ (rs4793665) was also studied in relation to the clearance of the metabolites. In addition, the model was used to assess whether failure of treatment was related to a difference in clearance of morphine or metabolites. The influence of failure of treatment was tested in the model as a binominal variable on the clearance of morphine and its metabolites, not with the purpose of explaining parameter variability but to identify a possible association between failure of the treatment and clearance.

\section{Results}

\subsection{Patients}

The dataset contained 410 samples from 49 patients (Table 2). Treatment with oral and subcutaneous morphine in relation to the observations for all patients is shown in
Table 2 Baseline characteristics

\begin{tabular}{|c|c|c|}
\hline Characteristics $(n=49)$ & No & $\begin{array}{l}\% \text { or } \\
\text { range }\end{array}$ \\
\hline Median age, years & 60 & $38-80$ \\
\hline \multicolumn{3}{|l|}{ Gender } \\
\hline Male & 27 & 55 \\
\hline Female & 22 & 45 \\
\hline Median weight, kg & 83 & $53-140$ \\
\hline \multicolumn{3}{|l|}{ Body mass index, $\mathrm{kg} / \mathrm{m}^{2}$} \\
\hline Underweight, $<18.5$ & 1 & 2 \\
\hline Normal range, $18.5-25$ & 13 & 27 \\
\hline Overweight, $25-30$ & 20 & 41 \\
\hline Obese, $30-40$ & 13 & 27 \\
\hline Severely obese, $>40$ & 2 & 4 \\
\hline \multicolumn{3}{|l|}{ Race } \\
\hline Caucasian & 44 & 90 \\
\hline Latin American & 1 & 2 \\
\hline Unknown/other & 4 & 8 \\
\hline Median WHO performance status & 2 & $0-3$ \\
\hline \multicolumn{3}{|l|}{ Primary tumor localization } \\
\hline Breast & 11 & 22 \\
\hline Colorectal & 7 & 14 \\
\hline Prostate & 6 & 12 \\
\hline Sarcoma & 4 & 8 \\
\hline Other & 21 & 43 \\
\hline Distant metastasis present & 44 & 89 \\
\hline Median creatinine, $\mu \mathrm{mol} / \mathrm{L}$ & 72 & $25-190$ \\
\hline $\begin{array}{l}\text { Median estimated glomerular filtration rate, } \mathrm{mL} / \\
\min / 1.73 \mathrm{~m}^{2}\end{array}$ & 81 & $33>90$ \\
\hline Median serum albumin, $\mathrm{g} / \mathrm{L}$ & 40 & $28-47$ \\
\hline \multicolumn{3}{|l|}{ Routes of administration during sampling } \\
\hline Subcutaneous & 28 & 57 \\
\hline Oral extended and immediate release & 12 & 24 \\
\hline Oral immediate release only & 6 & 12 \\
\hline Both oral and subcutaneous consecutively & 3 & 6 \\
\hline \multicolumn{3}{|l|}{$U G T 2 B 7 G>A$} \\
\hline GG, wild type & 14 & 29 \\
\hline GA, heterozygous & 26 & 53 \\
\hline AA, variant & 9 & 20 \\
\hline \multicolumn{3}{|l|}{$S L C 22 A 1$} \\
\hline 2 active alleles & 26 & 53 \\
\hline 1 active allele/ 1 inactive allele & 18 & 37 \\
\hline 2 inactive alleles & 5 & 10 \\
\hline \multicolumn{3}{|l|}{$A B C C 3 C>T$} \\
\hline $\mathrm{CC}$, wild type & 5 & 10 \\
\hline CT, heterozygous & 28 & 57 \\
\hline $\mathrm{TT}$, variant & 16 & 33 \\
\hline
\end{tabular}

UGT2B7 uridine $5^{\prime}$-diphospho-glucuronosyltransferase 2B7, $S L C 22 \mathrm{~A} 1$ solute carrier family $22 \mathrm{~A}$ member $1, A B C C 3$ ATP-binding cassette $\mathrm{C} 3$ 


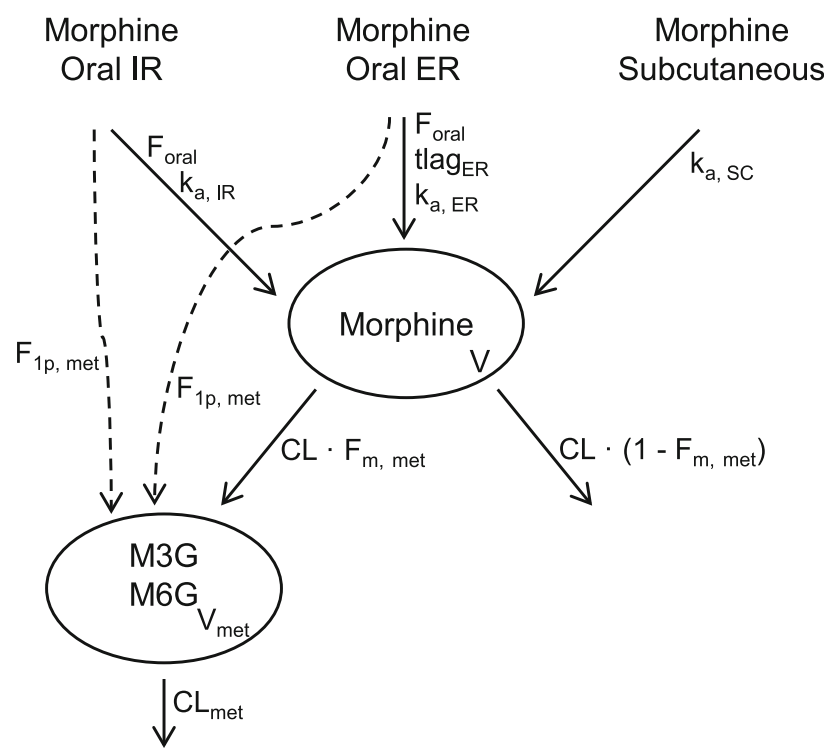

Fig. 1 Pharmacokinetic model developed to describe plasma concentrations of morphine and its metabolites (M3G and M6G) following oral IR, oral ER and subcutaneous administration. $C L$ morphine clearance, $C L_{m e t}$ metabolite clearance, $E R$ extended release, $F_{l p \text {, met }}$ fraction of morphine converted to metabolites in first-pass effect, $F_{m, m e t}$ fraction of morphine clearance forming metabolites, $F_{\text {oral }}$ oral bioavailability, $I R$ immediate release, $k_{a, E R}$ absorption rate constant for oral ER morphine, $k_{a, I R}$ absorption rate constant for oral IR morphine, $k_{a}, S C$ absorption rate constant for subcutaneous morphine, $M 3 G$ morphine-3-glucuronide, $M 6 G$ morphine-6-glucuronide, $\operatorname{tlag}_{E R}$ absorption lag-time for oral ER morphine, $V$ morphine volume of distribution, $V_{m e t}$ metabolites volume of distribution

electronic supplementary Fig. 1, and observations in relation to time after first dose are shown in electronic supplementary Fig. 2. Before the start of treatment with morphine, and/or inclusion in the study, 13 patients were opioid-naive, 11 were treated with fentanyl, 19 were treated with oxycodone, and six patients were already treated with morphine. Of these, five patients were treated with oral ER morphine and one was treated with continuous subcutaneous administration. The median treatment doses were $2 \mathrm{mg} / \mathrm{h}$ for continuous and bolus subcutaneous morphine (ranges $0.6-14 \mathrm{mg} / \mathrm{h}$ and $0.6-10 \mathrm{mg}$, respectively), $40 \mathrm{mg}$ twice daily for oral ER morphine (range $10-150 \mathrm{mg}$ ) and $10 \mathrm{mg}$ for oral IR morphine (range 5-60 mg). Creatinine values were missing for four patients and were imputed based on linear regression of the available values of eGFR on age and gender. In seven patients, baseline eGFR was between 30 and $60 \mathrm{~mL} / \mathrm{min} / 1.73 \mathrm{~m}^{2}$ (range $33-57 \mathrm{~mL} / \mathrm{min} / 1.73 \mathrm{~m}^{2}$, median $43 \mathrm{~mL} / \mathrm{min} /$ $\left.1.73 \mathrm{~m}^{2}\right)$. All other patients $(n=38)$ had an eGFR $\geq 60 \mathrm{~mL} / \mathrm{min} / 1.73 \mathrm{~m}^{2}$. In 12 of 43 patients treated with long-acting/continuous morphine, the outcome of treatment was classified as failure, in all due to the occurrence of dose-limiting side effects.

\subsection{Morphine Pharmacokinetics}

The pharmacokinetics of subcutaneous and oral morphine was adequately described by a one-compartment model with separate first-order absorption processes for each route. Parameters describing the absorption phases for subcutaneous and oral IR morphine were fixed to literature values $[27,28]$, and the value of the absorption rate constant for oral ER morphine was estimated $(p<0.001$ when compared with a fixed value of $\left.0.8 \mathrm{~h}^{-1}\right)$. The fractions of total morphine clearance forming $\mathrm{M} 3 \mathrm{G}$ and $\mathrm{M} 6 \mathrm{G}$ were fixed to 0.57 and 0.10 , respectively [4-6].

The pharmacokinetics of M3G and M6G were appropriately described by first-order systemic and additional first-pass formation and first-order elimination according to a one-compartment model (Fig. 1). Note that given the parameterization of the model (fixed and estimated fractions of formation), the estimated disposition parameters reflect true, and not apparent, values. The inclusion of firstpass metabolism statistically significantly improved the fit of the parent-metabolite model $(p<0.001)$. The metabolite disposition parameters were estimated to common values, and the estimation of separate clearance and volume parameters for each metabolite was not found to be statistically significant $(p>0.01)$. The final population model parameters for morphine, M3G and M6G are presented in Table 3.

The model was found to fit the data well, as shown by the absence of major systematic trends in the goodness-offit plots and pcVPCs (Fig. 2), with only a small tendency of overprediction of variability at low concentrations.

Allometric body weight with theory-based exponents was included a priori on all disposition parameters of all entities [35]. Age did not statistically significantly improve the model fit $(p>0.01)$. The inclusion of an effect of gender on clearance of morphine resulted in a decrease of $17.0 \%$ for females $(p>0.01)$ but was not retained in the model. The clearance of the metabolites was found to change with eGFR $(p<0.001)$ and increased $0.602 \mathrm{~L} / \mathrm{h}$ with every increase in eGFR of $10 \mathrm{~mL} / \mathrm{min} / 1.73 \mathrm{~m}^{2}$ up to an eGFR of $90 \mathrm{~mL} / \mathrm{min} / 1.73 \mathrm{~m}^{2}$, above which clearance was constant (Fig. 3).

The mean area under the plasma concentration-time curve (AUC) molar ratios for a typical patient (weight $70 \mathrm{~kg}$ and eGFR of $81 \mathrm{~mL} / \mathrm{min} / 1.73 \mathrm{~m}^{2}$ ) following oral morphine compared with the subcutaneous route of administration for the same dose were: M3G/morphine 29.7:1 vs. 11.1:1; M6G/morphine 5.26:1 vs. 1.95:1; and M3G/M6G 5.65:1 vs. 5.70:1. The concentration ratios over time and the respective model predictions by route of administration are shown in Fig. 4. 
Table 3 Population pharmacokinetic parameter estimates for morphine, M3G and M6G following subcutaneous and oral administration of morphine

\begin{tabular}{|c|c|c|c|c|}
\hline Parameter (units) & Description & Estimate & $\operatorname{SIR~RSE}^{\mathrm{a}}(\%)$ & SIR $95 \% \mathrm{CI}$ \\
\hline \multicolumn{5}{|l|}{ Morphine } \\
\hline$t_{\text {lag, ER }}(\mathrm{h})$ & Absorption lag-time for oral extended-release & 0.25 fixed & NA & NA \\
\hline$k_{\mathrm{a}, \mathrm{sC}}\left(\mathrm{h}^{-1}\right)$ & Absorption rate constant for subcutaneous & 3.96 fixed & NA & NA \\
\hline$k_{\mathrm{a}, \mathrm{IR}}\left(\mathrm{h}^{-1}\right)$ & $\begin{array}{l}\text { Absorption rate constant for oral immediate } \\
\text { release }\end{array}$ & 6.00 fixed & NA & NA \\
\hline$k_{\mathrm{a}, \mathrm{ER}}\left(\mathrm{h}^{-1}\right)$ & $\begin{array}{l}\text { Absorption rate constant for oral extended } \\
\text { release }\end{array}$ & 0.221 & 17.7 & $0.155-0.306$ \\
\hline$F_{\text {oral }}(\%)^{\mathrm{b}}$ & Oral bioavailability & 0.372 & NA & NA \\
\hline $\mathrm{CL}_{70 \mathrm{~kg}}(\mathrm{~L} / \mathrm{h})^{\mathrm{c}}$ & Clearance & 91.9 & 3.91 & $85.8-99.9$ \\
\hline$V_{70 \mathrm{~kg}}(\mathrm{~L})^{\mathrm{c}}$ & Volume of distribution & 278 & 12.3 & $221-351$ \\
\hline \multicolumn{5}{|l|}{$\mathrm{M} 3 \mathrm{G}$ and $\mathrm{M} 6 \mathrm{G}$} \\
\hline$F_{\mathrm{m}, \mathrm{M} 3 \mathrm{G}}$ & Fraction of morphine clearance forming $\mathrm{M} 3 \mathrm{G}$ & 0.573 fixed & NA & NA \\
\hline$F_{\mathrm{m}, \mathrm{M} 6 \mathrm{G}}$ & Fraction of morphine clearance forming M6G & 0.104 fixed & NA & NA \\
\hline$\theta_{1}^{\mathrm{b}}$ & $\begin{array}{l}\text { Parameter estimated to derive } F_{\text {oral, }} F_{1 \mathrm{p} \mathrm{M} 3 \mathrm{G}} \\
\text { and } F_{1 \mathrm{p} \text { M6G }}\end{array}$ & 0.170 & 10.4 & $0.136-0.206$ \\
\hline$\theta_{2}{ }^{\mathrm{b}}$ & $\begin{array}{l}\text { Parameter estimated to derive } F_{\text {oral, }} F_{1 \mathrm{p} \text { M3G }} \\
\text { and } F_{1 \mathrm{p} \text { M6G }}\end{array}$ & 0.953 & 8.95 & $0.796-1.14$ \\
\hline$\theta_{3}{ }^{\mathrm{b}}$ & $\begin{array}{l}\text { Parameter estimated to derive } F_{\text {oral }}, F_{1 \mathrm{p} \mathrm{M} 3 \mathrm{G}} \\
\text { and } F_{1 \mathrm{p} \text { M6G }}\end{array}$ & 0.565 & 30.3 & $0.310-1.01$ \\
\hline$F_{1 \mathrm{p}, \mathrm{M} 3 \mathrm{G}}{ }^{\mathrm{b}}$ & $\begin{array}{l}\text { Fraction of morphine converted to M3G in } \\
\text { first-pass effect }\end{array}$ & 0.355 & NA & NA \\
\hline$F_{1 \mathrm{p}, \mathrm{M} 6 \mathrm{G}^{\mathrm{b}}}$ & $\begin{array}{l}\text { Fraction of morphine converted to M6G in } \\
\text { first-pass effect }\end{array}$ & 0.0631 & NA & NA \\
\hline $\mathrm{CL}_{\text {met, } 70 \mathrm{~kg}}(\mathrm{~L} / \mathrm{h})^{\mathrm{d}}$ & Clearance (common for metabolites) & 4.71 & 5.24 & $4.24-5.20$ \\
\hline$V_{\text {met, } 70 \mathrm{~kg}}(\mathrm{~L})^{\mathrm{c}}$ & $\begin{array}{l}\text { Volume of distribution (common for } \\
\text { metabolites) }\end{array}$ & 25.8 & 6.12 & $22.8-29.0$ \\
\hline eGFR on $\mathrm{CL}_{\text {met, } 70 \mathrm{~kg}}{ }^{\mathrm{d}}$ & $\begin{array}{l}\text { Fractional change in } \mathrm{CL}_{\text {met, }} 70 \mathrm{~kg} \text { per } \mathrm{mL} / \mathrm{min} / \\
1.73 \mathrm{~m}^{2} \text { eGFR relative to } \mathrm{CL}_{\text {met, }} 70 \mathrm{~kg} \text { for } \\
\text { subject with eGFR of } 81 \mathrm{~mL} / \mathrm{min} / 1.73 \mathrm{~m}^{2}\end{array}$ & 0.0128 & 12.9 & $0.00924-0.0156$ \\
\hline \multicolumn{5}{|l|}{ Interindividual variability } \\
\hline$k_{\mathrm{a}, \text { all }}(\% \mathrm{CV}[\eta$-shrinkage $])$ & & $71.0[25.3]$ & NA & NA \\
\hline $\mathrm{CL}_{70 \mathrm{~kg}}(\% \mathrm{CV}[\eta$-shrinkage $])$ & & $22.2[17.9]$ & 12.9 & $16.9-27.8$ \\
\hline$V_{70 \mathrm{~kg}}(\% \mathrm{CV}[\eta$-shrinkage $])$ & & $74.7[21.4]$ & 9.71 & $60.4-88.6$ \\
\hline $\mathrm{CL}_{\mathrm{M} 3 \mathrm{G}}(\% \mathrm{CV}[\eta$-shrinkage $])$ & & $36.2[6.28]$ & 10.6 & $29.5-44.4$ \\
\hline $\mathrm{CL}_{\mathrm{M} 6 \mathrm{G}}(\% \mathrm{CV}[\eta$-shrinkage $])$ & & $36.8[7.00]$ & 11.8 & $29.6-46.2$ \\
\hline Correlation $\mathrm{CL}_{\mathrm{M} 3 \mathrm{G}}-\mathrm{CL}_{\mathrm{M} 6 \mathrm{G}}{ }^{\mathrm{e}}$ & & 0.912 & 11.8 & $0.864-0.952$ \\
\hline$V_{\mathrm{M} 3 \mathrm{G}}(\% \mathrm{CV}[\eta$-shrinkage $])$ & & $24.7[30.7]$ & 18.4 & $17.0-34.0$ \\
\hline$V_{\mathrm{M} 6 \mathrm{G}}(\% \mathrm{CV}[\eta$-shrinkage $])$ & & $24.3[39.0]$ & 20.5 & $16.3-34.6$ \\
\hline$\theta_{1}(\% \mathrm{CV}[\eta$-shrinkage $])$ & & $15.0[62.7]$ & 18.7 & $8.91-19.9$ \\
\hline$\theta_{3}(\% \mathrm{CV}[\eta$-shrinkage $])$ & & $98.2[57.1]$ & 25.1 & $50.1-146$ \\
\hline \multicolumn{5}{|l|}{ Residual variability } \\
\hline Morphine (\% CV [ $\varepsilon$-shrinkage]) & Proportional residual error for morphine & $28.6[8.45]$ & 4.31 & $26.5-31.2$ \\
\hline M3G (\%CV [ع-shrinkage]) & Proportional residual error for $\mathrm{M} 3 \mathrm{G}$ & $20.0[8.00]$ & 4.14 & $18.5-21.7$ \\
\hline M6G (\%CV [ع-shrinkage]) & Proportional residual error for $\mathrm{M} 6 \mathrm{G}$ & $23.9[8.00]$ & 4.04 & $22.2-26.0$ \\
\hline Correlation morphine- $\mathrm{M}^{3} \mathrm{G}^{\mathrm{e}}$ & & 0.420 & 7.11 & $0.340-0.504$ \\
\hline Correlation morphine-M6G ${ }^{\mathrm{e}}$ & & 0.386 & 7.57 & $0.302-0.477$ \\
\hline
\end{tabular}


Table 3 continued

\begin{tabular}{llllc}
\hline Parameter (units) & Description & Estimate & SIR RSE ${ }^{\mathrm{a}}(\%)$ & SIR 95\% CI \\
\hline Correlation M3G-M6G & & 0.918 & 4.29 & $0.901-0.934$ \\
\hline
\end{tabular}

$C I$ confidence interval, $C V$ coefficient of variation, $e G F R$ estimated glomerular filtration rate, $M 3 G$ morphine-3-glucuronide, $M 6 G$ morphine-6glucuronide, $N A$ not available, $R S E$ relative standard error, SIR sampling/importance resampling

${ }^{\text {a }}$ For interindividual and residual variability, \%RSE is reported on the standard deviation scale

${ }^{\mathrm{b}} F_{\text {oral }}=1 /\left(1+\theta_{1}+\theta_{2}+\theta_{3}\right) ; F_{1 \mathrm{p}, \mathrm{M} 3 \mathrm{G}}=\theta_{2} /\left(1+\theta_{1}+\theta_{2}+\theta_{3}\right) ; F_{1 \mathrm{p}, \mathrm{M} 6 \mathrm{G}}=\theta_{1} /\left(1+\theta_{1}+\theta_{2}+\theta_{3}\right)$

${ }^{c}$ Value for a $70-\mathrm{kg}$ patient calculated as parameter $=$ estimate $_{70 \mathrm{~kg}} \times\left(\right.$ weight/70) ${ }^{1 \text { for volumes or } 0.75 \text { for clearances }}$

${ }^{\mathrm{d}}$ Value for a $70-\mathrm{kg}$ patient with $\mathrm{eGFR}=81 \mathrm{~mL} / \mathrm{min} / 1.73 \mathrm{~m}^{2}$ calculated as $\mathrm{CL}_{\text {met }}=4.71 \times(\text { weight/70 })^{0.75} \times(1+0.0128 \times(\mathrm{eGFR}-81))$

e Correlation of the off-diagonal estimate calculated as cov(omega1, omega2)/sqrt(var(omega1) $\times$ var(omega2)) or cov(sigma1, sigma2)/ $\operatorname{sqrt}(\operatorname{var}($ sigma 1$) \times \operatorname{var}($ sigma2) $)$

\subsection{Influence of Genetic Variants}

An effect of $U G T 2 B 7, S L C 22 A 1$ and ABCC3 SNPs on total clearance of morphine and morphine metabolic clearances to M3G or M6G could not be identified ( $p>0.01$ ). Similarly, an effect of $A B C C 3$ genotype on the clearance of the metabolites was not found $(p>0.01)$.

\subsection{Assessment of Treatment Failure in Relation to Metabolism}

Differences in clearance of morphine, M3G and M6G in patients in whom treatment with morphine failed $(n=12)$ compared with patients in whom treatment did not fail $(n=31)$ could not be identified ( $p>0.01$ in all cases).

\section{Discussion}

First, we developed a population pharmacokinetic model for morphine, M3G and M6G following subcutaneous and oral morphine administration from a high number of sparse samples. We found that a one-compartment model with separate first-order absorption processes for each route adequately describes the plasma concentrations of morphine, and a one-compartment model following first-order systemic and additional first-pass formation from morphine appropriately describes plasma concentrations of the metabolites. Our results are in line with literature data.

Pharmacokinetic data after subcutaneous administration are scarce. The model by Upton et al. [27], who reported a clearance of $79.8 \mathrm{~L} / \mathrm{h}$ in a population of 22 postoperative patients aged 50 years or over, was the basis for the morphine model. In a study by Stuart-Harris et al. [29] in six healthy volunteers, clearances of $83.1 \mathrm{~L} / \mathrm{h}$ (subcutaneous bolus), $95 \mathrm{~L} / \mathrm{h}$ (intravenously) and $127.5 \mathrm{~L} / \mathrm{h}$ (subcutaneous infusion) were reported. In a recent publication, a lower clearance of $47.5 \mathrm{~L} / \mathrm{h}$ was reported in a slightly older and terminally ill population, with (compared with our cohort) lower serum albumin values (median $26 \mathrm{~g} / \mathrm{L}$ ), shorter survival (median 33 days) and, most likely, lower body weight (not reported); these factors may suggest lower metabolic capacity and may explain the lower clearance in that study [36]. Thus, clearance in our study, estimated to be $92.9 \mathrm{~L} / \mathrm{h}$ for a patient weighing $70 \mathrm{~kg}$, is in reasonable agreement with previous data. In our analysis, we assumed complete bioavailability following subcutaneous administration. Although information available in the literature was limited, i.e. the studies comparing subcutaneous and intravenous administration usually involved a small number of patients and a crossover design was not used in all studies [29-31], we consider that the current literature supports the assumption made. The main consequence if this assumption is not true lies in the interpretation of the estimated pharmacokinetic parameters, i.e. they would correspond to apparent clearances and volumes of distribution, and oral bioavailability would be relative (to subcutaneous) instead of absolute.

Clearance for the metabolites was estimated to a common value of $4.71 \mathrm{~L} / \mathrm{h}$ for a subject weighing $70 \mathrm{~kg}$ and with eGFR of $81 \mathrm{~mL} / \mathrm{min} / 1.73 \mathrm{~m}^{2}$. The estimation of separate disposition parameters for M3G and M6G did not statistically significantly improve the model, proposing that these entities have the same clearance and volume of distribution, a finding that is true or may be due to modeling assumptions leading to difficulties in distinguishing different pharmacokinetic characteristics of the metabolites. Thus, the different pharmacokinetic profiles of the metabolites depend exclusively on the fraction of systemic (subcutaneous and oral) and first-pass formation (oral) of the metabolites, which is in line with the observed strong correlation $\left(R^{2}=0.963\right)$ of the metabolites as reported in other studies [37, 38]. Furthermore, the suggestion of similar pharmacokinetic estimates for the metabolites is supported by results from independent pharmacokinetic studies following intravenous administration of M6G and M3G to healthy volunteers, which reported clearances for M6G and M3G of 10-11 and $10 \mathrm{~L} / \mathrm{h}$, respectively [39-41]. 

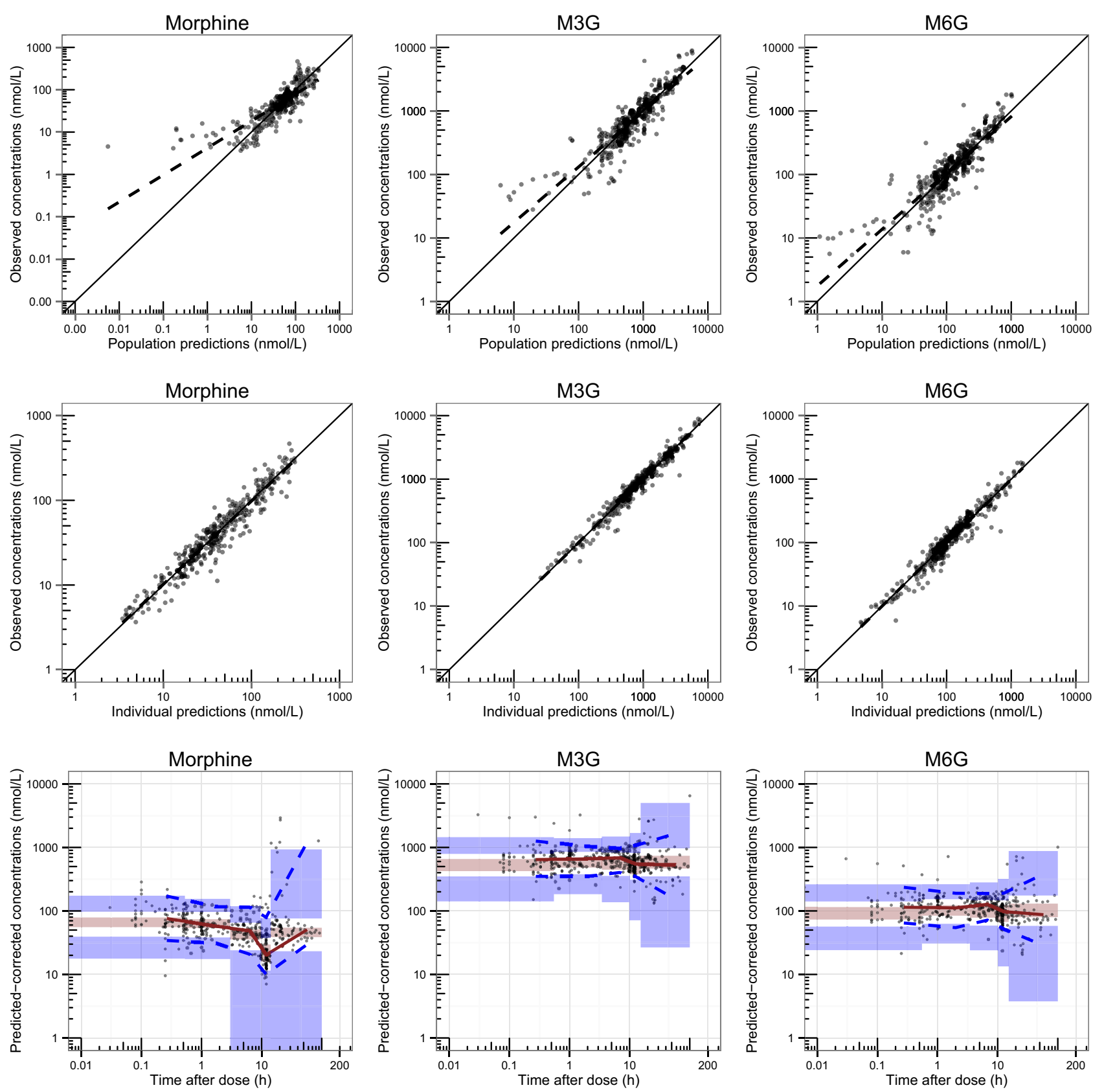

Fig. 2 Prediction- and simulation-based diagnostics for the final population pharmacokinetic model. Observed concentrations of morphine, M3G and M6G versus population predictions (upper panel), and observed concentrations versus individual population predictions (middle panel); the solid line represents a unity line and the dashed line represents a linear tendency line. Prediction-corrected

Moreover, the lower clearance estimated in our study $(4.7 \mathrm{~L} / \mathrm{h})$ is reasonable given the lower renal function in cancer patients compared with healthy volunteers, and is in agreement with clearance for $\mathrm{M} 6 \mathrm{G}$ of $5.7 \mathrm{~L} / \mathrm{h}$ following intravenous administration in cancer patients [42]. In the four cited studies, volume of distribution was estimated in the range of $20-30 \mathrm{~L}$, which is consistent with our estimate. visual predictive checks (lower panel) through 1000 replications; dots represent the predicted-corrected concentrations of each entity, the solid red line and dashed blue lines represent the observed median and 5th and 95th observed percentiles, and the shaded areas represent the $95 \%$ confidence interval for the respective percentiles. $M 3 G$ morphine-3-glucuronide, $M 6 G$ morphine-6-glucuronide

Concentration-time data following the administration of subcutaneous and oral morphine allowed estimation of the oral morphine bioavailability $(37.2 \%)$ and, in addition, the fractions of the oral morphine dose that undergo first-pass metabolism to M3G (35.5\%) and M6G (6.31\%). It is not expected that the fractions are in agreement with the Fm, i.e. the fractions of morphine clearance forming the two metabolites. The fraction of the dose formed into a 
Fig. 3 M3G and M6G clearance in relation to eGFR and body weight. $e G F R$ glomerular filtration rate, $M 3 G$ morphine-3-glucuronide, $M 6 G$ morphine-6-glucuronide

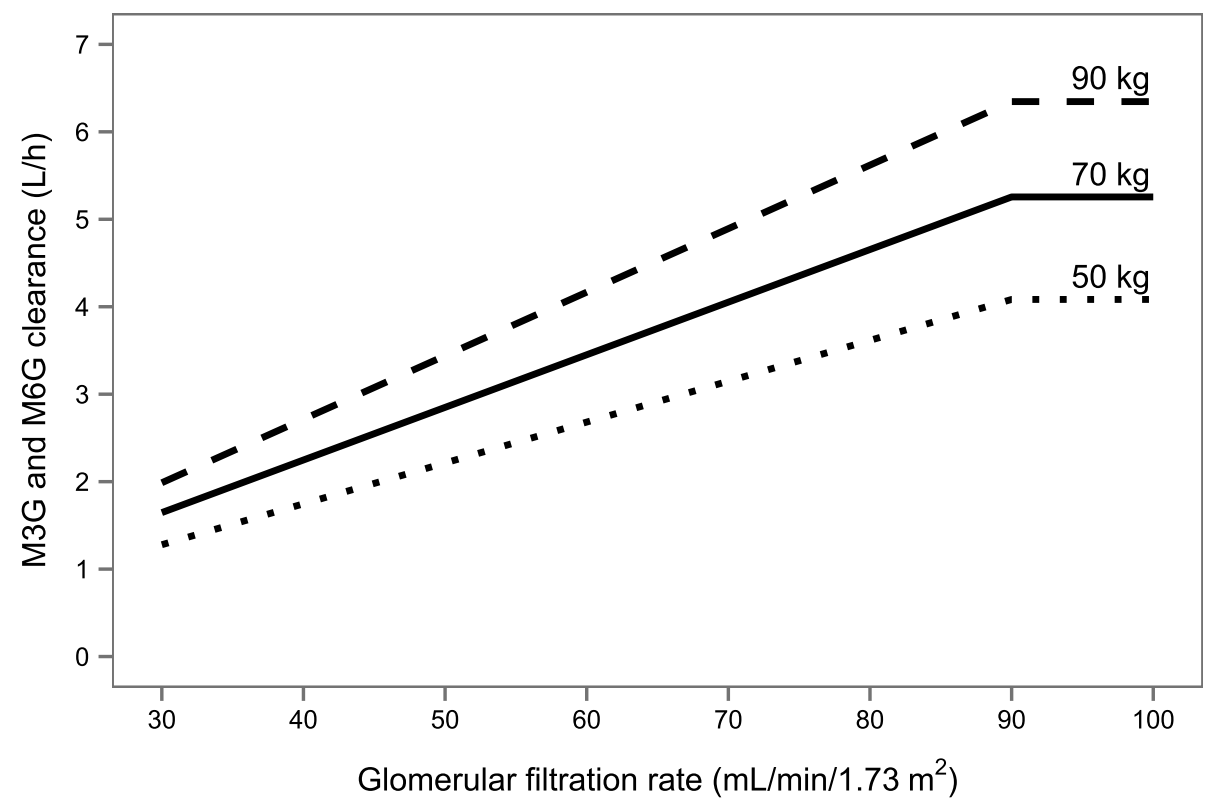

metabolite in the first pass is dependent on several factors: whether metabolism occurs in the intestinal wall in addition to the liver; whether all metabolites are formed in the first passage (i.e. whether total clearance is equal to hepatic clearance); and the blood-to-plasma ratio of morphine. The values estimated are in line with hepatic first-pass metabolism only (for all pathways), but this is not solid evidence of lack of intestinal wall formation.

As expected, the subcutaneous route of administration, which avoids first-pass metabolism, resulted in lower metabolite:morphine concentration ratios compared with the oral route. According to Hasselstrom and Sawe [5], and supported by our data, this difference is due to higher morphine plasma concentrations, and therefore the AUCs of the metabolites formed following both routes of morphine administration are similar. The observed and modelpredicted ratio $\mathrm{M} 3 \mathrm{G}: \mathrm{M} 6 \mathrm{G}$ remained constant regardless of the level of renal impairment or route of administration. The clinical consequences of the differences in metabolite:morphine ratios are uncertain. We could only find one study comparing oral and subcutaneous administration using a crossover design [23]. This study reported less nausea and somnolence during treatment with subcutaneous morphine, a finding that we recognize from our daily clinical practice. However, the relationship between plasma concentrations of morphine and its metabolites and clinical effects is not clear because some studies have failed to show a correlation [43-45], while others reported an association [9, 37, 46]. Although we did not perform a full pharmacokinetic-pharmacodynamic analysis, we tried to identify an association between outcome of treatment and clearance of morphine. The outcome of treatment may not be associated with a different clearance of morphine, and other factors may be more important in this regard. The relation between clearances and plasma concentrations of morphine and the metabolites and outcomes of treatment deserves further study.

Second, in an attempt to explain variability in pharmacokinetic parameters, we studied the role of several clinical and genetic covariates on the clearances of morphine and the metabolites. In our study, inclusion of both age and gender did not statistically significantly improve the model, although we estimated a $17 \%$ lower clearance in females. Reported data on the effects of age are conflicting. Age was reported to predict postoperative morphine requirements [47], and pharmacokinetic studies have reported either lower clearances and volume of distribution in elderly patients [20] or higher plasma concentrations of M6G and/or M3G [48, 49], while others found no significant impact of age [50]. A possible explanation for these findings is the fact that in most studies renal function, which declines with age, was not taken into account. However, in the study by Klepstad et al. [49], serum creatinine and age were found to be independent contributors to outcome in a multivariable analysis.

With regard to gender, in a systematic review and metaanalysis, Niesters et al. [21] found that women display greater opioid analgesia than men and this effect was largest when the analysis was restricted to patient-controlled analgesia studies with morphine. However, it is unclear if this gender difference can be attributed to pharmacokinetic differences. While McQuay et al. [48] found lower plasma concentrations of morphine and $\mathrm{M} 6 \mathrm{G}$ in men compared with women, the effect of gender was also non-significant in other modeling studies [27, 50].

Furthermore, clearance of the metabolites was found to be a function of body weight and renal function (Fig. 3), 
Fig. 4 Observed and simulated (1000 replications) metabolic concentration ratios

(M3G:morphine,

M6G:morphine and M3G:M6G) over time stratified by route of administration; dots represent the observed metabolic concentrations ratios, the solid red line represents the observed median, and the shaded area represents the $95 \%$ confidence interval for the simulated median. $M 3 G$ morphine-3glucuronide, $M 6 G$ morphine-6glucuronide
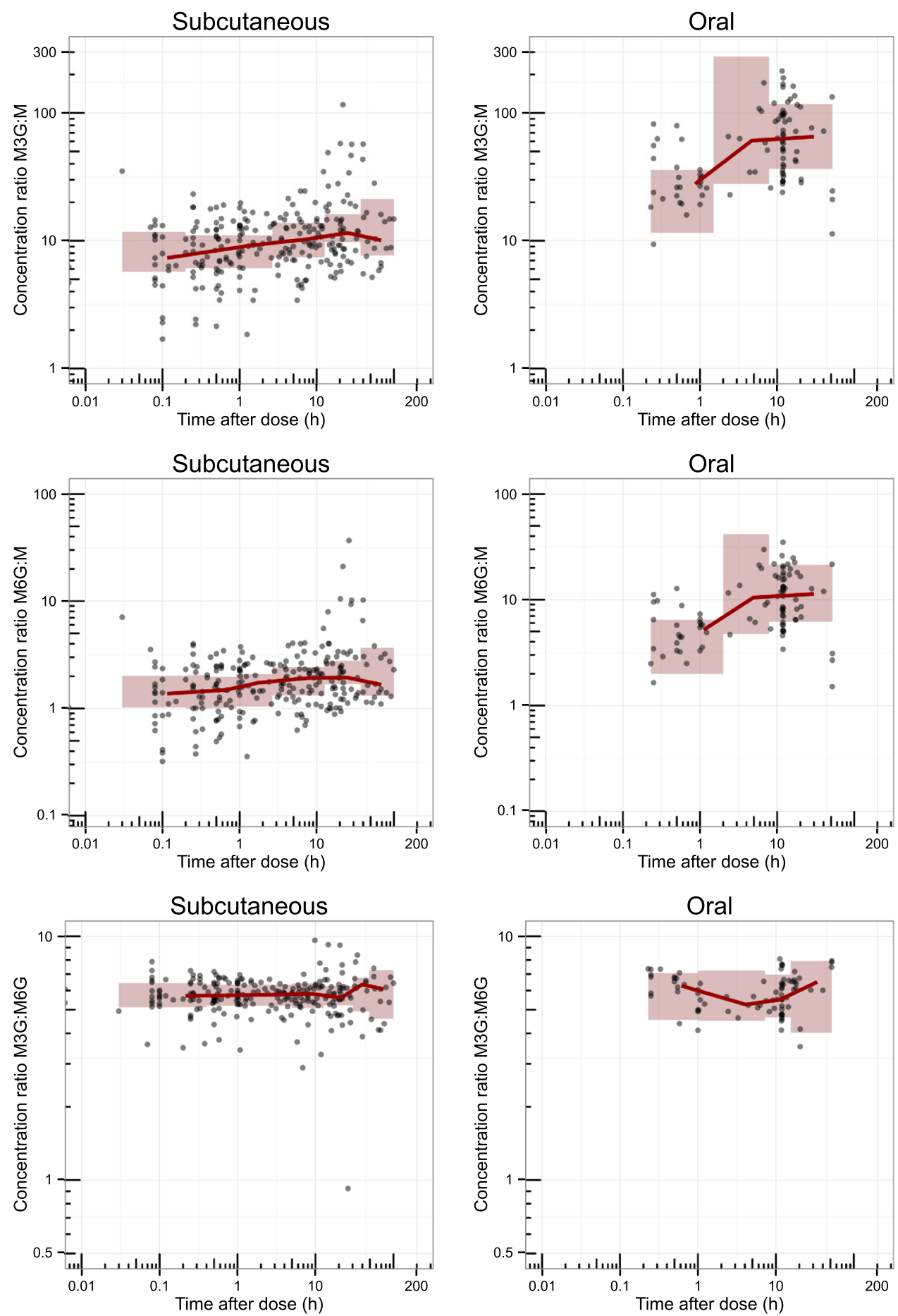

while no correlation was found between these two (data not shown). The consequence of this combined finding for dose recommendation is not clear, and would demand to simultaneously take into account the systemic exposure of morphine and its metabolites. Although accumulation of M3G and M6G in patients with impaired renal function is widely reported [51], data on the clinical effects of morphine treatment in these patients are scarce and conflicting.
Reducing the frequency of administration or the dose are carefully suggested in guidelines [1, 52], but opioid rotation to an opioid without renally excreted active metabolites, such as fentanyl, should also be considered.

In addition, we did not identify the significant effects of genetic variants in transporters (OCT1, ABCC3) and the phase II metabolizing enzyme (UGT2B7) on morphine pharmacokinetics. Remarkably, almost all of the 
previously identified effects of these genetic variants were found in children and mainly in small patient populations (Table 1). In our adult population, we were unable to confirm previously identified effects, which may be caused by lower rates of glucuronidation in children and possibly overcapacity in adult livers. Additionally, the absence of a genotypic OCT1 effect could be due to construction of the OCT1 haplotype in the current study. Recently, a study addressing worldwide genetic variability within this gene, and assessing the effect of several genetic variants (among others $S L C 22 A 1 * 2-* 6$ alleles) on 10 probe compounds, found that the effect of the $* 2$ allele on the transport function is substrate-dependent [53]. This makes the $* 2$ allele a rather reduced function allele against morphine than total loss-of-function, as previously suggested $[54,55]$.

\section{Conclusions}

We found that a one-compartment model adequately described the pharmacokinetics of morphine after subcutaneous and oral administration, and a one-compartment model following first-order systemic and additional firstpass formation from morphine appropriately described the plasma concentrations of the metabolites. The estimated relative bioavailability of $37.2 \%$ for oral morphine confirms the dose conversion ratio of 1:3 when converting subcutaneous to oral morphine. Age and gender did not significantly influence the clearance of morphine, while clearance of the metabolites was found to be a function of body weight and glomerular filtration rate. We identified no significant effects of polymorphisms in UGT2B7, SLC22AI and $A B C C 3$, and no difference in morphine and metabolite clearance between patients in whom treatment failed versus patients in whom treatment did not fail. Further research is therefore needed to explain the variability in treatment doses as well as clinical outcomes.

Acknowledgements The authors thank Tilly Baan for her help with the conduct of this study.

\section{Compliance with Ethical Standards}

This study was approved by the Medical Ethics Review Board (MEC 09.332) and was conducted in accordance with the Declaration of Helsinki. The trial was registered in the Dutch Trial Register (Trial Registration ID: NTR4369), and written informed consent was obtained from all patients.

Funding No sources of funding were used in the preparation of this manuscript. This study was financially supported by the Netherlands Organisation for Health Research and Development (ZonMw Project Number 1151.0014), Cornelis Vrolijk Fund and Stichting Voorzieningenfonds Palliatieve Zorg Dirksland.
Conflict of interest Astrid W. Oosten, João A. Abrantes, Siv Jönsson, Maja Matic, Ron H.N. van Schaik, Peter de Bruijn, Carin C.D. van der Rijt and Ron H.J. Mathijssen have no conflicts of interest relevant to the content of this paper.

Open Access This article is distributed under the terms of the Creative Commons Attribution-NonCommercial 4.0 International License (http://creativecommons.org/licenses/by-nc/4.0/), which permits any noncommercial use, distribution, and reproduction in any medium, provided you give appropriate credit to the original author(s) and the source, provide a link to the Creative Commons license, and indicate if changes were made.

\section{References}

1. Caraceni A, Hanks G, Kaasa S, Bennett MI, Brunelli C, Cherny $\mathrm{N}$, et al. Use of opioid analgesics in the treatment of cancer pain: evidence-based recommendations from the EAPC. Lancet Oncol. 2012;13(2):e58-68.

2. Lugo RA, Kern SE. Clinical pharmacokinetics of morphine. J Pain Palliat Care Pharmacother. 2002;16(4):5-18.

3. Glare PA, Walsh TD. Clinical pharmacokinetics of morphine. Ther Drug Monit. 1991;13(1):1-23.

4. Yeh SY, Gorodetzky CW, Krebs HA. Isolation and identification of morphine 3- and 6-glucuronides, morphine 3,6-diglucuronide, morphine 3-ethereal sulfate, normorphine, and normorphine 6-glucuronide as morphine metabolites in humans. J Pharm Sci. 1977;66(9):1288-93.

5. Hasselstrom J, Sawe J. Morphine pharmacokinetics and metabolism in humans. Enterohepatic cycling and relative contribution of metabolites to active opioid concentrations. Clin Pharmacokinet. 1993;24(4):344-54.

6. Sawe J. High-dose morphine and methadone in cancer patients. Clinical pharmacokinetic considerations of oral treatment. Clin Pharmacokinet. 1986;11(2):87-106.

7. Klimas R, Mikus G. Morphine-6-glucuronide is responsible for the analgesic effect after morphine administration: a quantitative review of morphine, morphine-6-glucuronide, and morphine-3glucuronide. Br J Anaesth. 2014;113(6):935-44.

8. Osborne R, Joel S, Trew D, Slevin M. Analgesic activity of morphine-6-glucuronide. Lancet. 1988;1(8589):828.

9. Portenoy RK, Thaler HT, Inturrisi CE, Friedlander-Klar H, Foley KM. The metabolite morphine-6-glucuronide contributes to the analgesia produced by morphine infusion in patients with pain and normal renal function. Clin Pharmacol Ther. 1992;51(4):422-31.

10. Gardmark M, Karlsson MO, Jonsson F, Hammarlund-Udenaes M. Morphine-3-glucuronide has a minor effect on morphine antinociception. Pharmacodynamic modeling. J Pharm Sci. 1998;87(7):813-20.

11. Gong QL, Hedner T, Hedner J, Bjorkman R, Nordberg G. Antinociceptive and ventilatory effects of the morphine metabolites: morphine-6-glucuronide and morphine-3-glucuronide. Eur J Pharmacol. 1991;193(1):47-56.

12. Penson RT, Joel SP, Bakhshi K, Clark SJ, Langford RM, Slevin ML. Randomized placebo-controlled trial of the activity of the morphine glucuronides. Clin Pharmacol Ther. 2000;68(6):667-76.

13. Bruera E, Brenneis C, Michaud M, Bacovsky R, Chadwick S, Emeno A, et al. Use of the subcutaneous route for the administration of narcotics in patients with cancer pain. Cancer. 1988;62(2):407-11. 
14. Drexel H, Dzien A, Spiegel RW, Lang AH, Breier C, Abbrederis $\mathrm{K}$, et al. Treatment of severe cancer pain by low-dose continuous subcutaneous morphine. Pain. 1989;36(2):169-76.

15. Neafsey PJ. Efficacy of continuous subcutaneous infusion in patients with cancer pain. Home Healthc Nurse. 2005;23(7):421-3.

16. Vermeire A, Remon JP, Rosseel MT, Belpaire F, Devulder J, Bogaert MG. Variability of morphine disposition during longterm subcutaneous infusion in terminally ill cancer patients. Eur J Clin Pharmacol. 1998;53(5):325-30.

17. Klepstad P, Hilton P, Moen J, Kaasa S, Borchgrevink PC, Zahlsen $\mathrm{K}$, et al. Day-to-day variations during clinical drug monitoring of morphine, morphine-3-glucuronide and morphine6-glucuronide serum concentrations in cancer patients. A prospective observational study. BMC Clin Pharmacol. 2004;4:7.

18. Riley J, Ross JR, Rutter D, Wells AU, Goller K, du Bois R, et al. No pain relief from morphine? Individual variation in sensitivity to morphine and the need to switch to an alternative opioid in cancer patients. Support Care Cancer. 2006;14(1):56-64.

19. Aubrun F, Salvi N, Coriat P, Riou B. Sex- and age-related differences in morphine requirements for postoperative pain relief. Anesthesiology. 2005;103(1):156-60.

20. Baillie SP, Bateman DN, Coates PE, Woodhouse KW. Age and the pharmacokinetics of morphine. Age Ageing. 1989;18(4):258-62.

21. Niesters M, Dahan A, Kest B, Zacny J, Stijnen T, Aarts L, et al. Do sex differences exist in opioid analgesia? A systematic review and meta-analysis of human experimental and clinical studies. Pain. 2010;151(1):61-8.

22. Hajj A, Khabbaz L, Laplanche JL, Peoc'h K. Pharmacogenetics of opiates in clinical practice: the visible tip of the iceberg. Pharmacogenomics. 2013;14(5):575-85.

23. Mikkelsen Lynch P, Butler J, Huerta D, Tsals I, Davidson D, Hamm S. A pharmacokinetic and tolerability evaluation of two continuous subcutaneous infusion systems compared to an oral controlled-release morphine. J Pain Symptom Manag. 2000;19(5):348-56.

24. Beal SL, Boeckmann AJ, Bauer RJ. NONMEM 7.3.0 Users Guides. Hanover: ICON Development Solutions; 1989-2013.

25. Keizer RJ, Karlsson MO, Hooker A. Modeling and simulation workbench for NONMEM: tutorial on Pirana, PsN, and Xpose. CPT Pharmacomet Syst Pharmacol. 2013;2:e50.

26. Ahn JE, Karlsson MO, Dunne A, Ludden TM. Likelihood based approaches to handling data below the quantification limit using NONMEM VI. J Pharmacokinet Pharmacodyn. 2008;35(4):401-21.

27. Upton RN, Semple TJ, Macintyre PE, Foster DJR. Population pharmacokinetic modelling of subcutaneous morphine in the elderly. Acute Pain. 2006;8(3):109-16.

28. Hunt A, Joel S, Dick G, Goldman A. Population pharmacokinetics of oral morphine and its glucuronides in children receiving morphine as immediate-release liquid or sustained-release tablets for cancer pain. J Pediatr. 1999;135(1):47-55.

29. Stuart-Harris R, Joel SP, McDonald P, Currow D, Slevin ML. The pharmacokinetics of morphine and morphine glucuronide metabolites after subcutaneous bolus injection and subcutaneous infusion of morphine. Br J Clin Pharmacol. 2000;49(3):207-14.

30. Waldmann CS, Eason JR, Rambohul E, Hanson GC. Serum morphine levels. A comparison between continuous subcutaneous infusion and continuous intravenous infusion in postoperative patients. Anaesthesia. 1984;39(8):768-71.

31. Starlander J, Melin-Johansson C, Jonsson H, Axelsson B. Oralparenteral conversion factor for morphine in palliative cancer care: a prospective randomized crossover pilot study. Pain Res Treat. 2011;2011:504034.
32. Karlsson MO, Savic RM. Diagnosing model diagnostics. Clin Pharmacol Ther. 2007;82(1):17-20.

33. Dosne AG BM, Harling K, Karlsson MO. Improving the estimation of parameter uncertainty distributions in nonlinear mixed effects models using sampling importance resampling. J Pharmacokinet Pharmacodyn. 2016. doi:10.1007/s10928-016-9487-8 (ePub 11 Oct 2016).

34. Bergstrand M, Hooker AC, Wallin JE, Karlsson MO. Predictioncorrected visual predictive checks for diagnosing nonlinear mixed-effects models. AAPS J. 2011;13(2):143-51.

35. Holford NH, Ma SC, Anderson BJ. Prediction of morphine dose in humans. Paediatr Anaesth. 2012;22(3):209-22.

36. Franken LG, Masman AD, de Winter BC, Koch BC, Baar FP, Tibboel D, et al. Pharmacokinetics of morphine, morphine-3glucuronide and morphine-6-glucuronide in terminally ill adult patients. Clin Pharmacokinet. 2016;55(6):697-709.

37. De Gregori S, Minella CE, De Gregori M, Tinelli C, Ranzani GN, Govoni S, et al. Clinical pharmacokinetics of morphine and its metabolites during morphine dose titration for chronic cancer pain. Ther Drug Monit. 2014;36(3):335-44.

38. Faura CC, Collins SL, Moore RA, McQuay HJ. Systematic review of factors affecting the ratios of morphine and its major metabolites. Pain. 1998;74(1):43-53.

39. Penson RT, Joel SP, Clark S, Gloyne A, Slevin ML. Limited phase I study of morphine-3-glucuronide. J Pharm Sci. 2001;90(11):1810-6.

40. Penson RT, Joel SP, Roberts M, Gloyne A, Beckwith S, Slevin ML. The bioavailability and pharmacokinetics of subcutaneous, nebulized and oral morphine-6-glucuronide. Br J Clin Pharmacol. 2002;53(4):347-54.

41. Hanna MH, Peat SJ, Knibb AA, Fung C. Disposition of morphine-6-glucuronide and morphine in healthy volunteers. Br J Anaesth. 1991;66(1):103-7.

42. Osborne R, Thompson P, Joel S, Trew D, Patel N, Slevin M. The analgesic activity of morphine-6-glucuronide. Br J Clin Pharmacol. 1992;34(2):130-8.

43. Klepstad P, Borchgrevink PC, Dale O, Zahlsen K, Aamo T, Fayers $\mathrm{P}$, et al. Routine drug monitoring of serum concentrations of morphine, morphine-3-glucuronide and morphine-6-glucuronide do not predict clinical observations in cancer patients. Palliat Med. 2003;17(8):679-87.

44. Quigley C, Joel S, Patel N, Baksh A, Slevin M. Plasma concentrations of morphine, morphine-6-glucuronide and morphine3 -glucuronide and their relationship with analgesia and side effects in patients with cancer-related pain. Palliat Med. 2003;17(2):185-90.

45. Somogyi AA, Nation RL, Olweny C, Tsirgiotis P, van Crugten J, Milne RW, et al. Plasma concentrations and renal clearance of morphine, morphine-3-glucuronide and morphine-6-glucuronide in cancer patients receiving morphine. Clin Pharmacokinet. 1993;24(5):413-20.

46. Gretton SK, Ross JR, Rutter D, Sato H, Droney JM, Welsh KI, et al. Plasma morphine and metabolite concentrations are associated with clinical effects of morphine in cancer patients. J Pain Symptom Manag. 2013;45(4):670-80.

47. Macintyre PE, Jarvis DA. Age is the best predictor of postoperative morphine requirements. Pain. 1996;64(2):357-64.

48. McQuay HJ, Carroll D, Faura CC, Gavaghan DJ, Hand CW, Moore RA. Oral morphine in cancer pain: influences on morphine and metabolite concentration. Clin Pharmacol Ther. 1990;48(3):236-44.

49. Klepstad P, Dale O, Kaasa S, Zahlsen K, Aamo T, Fayers P, et al. Influences on serum concentrations of morphine, M6G and M3G during routine clinical drug monitoring: a prospective survey in 300 adult cancer patients. Acta Anaesthesiol Scand. 2003;47(6):725-31. 
50. Mazoit JX, Butscher K, Samii K. Morphine in postoperative patients: pharmacokinetics and pharmacodynamics of metabolites. Anesth Analg. 2007;105(1):70-8.

51. Aitkenhead AR, Vater M, Achola K, Cooper CM, Smith G. Pharmacokinetics of single-dose i.v. morphine in normal volunteers and patients with end-stage renal failure. $\mathrm{Br} \mathrm{J}$ Anaesth. 1984;56(8):813-9.

52. King S, Forbes K, Hanks GW, Ferro CJ, Chambers EJ. A systematic review of the use of opioid medication for those with moderate to severe cancer pain and renal impairment: a European Palliative Care Research Collaborative opioid guidelines project. Palliat Med. 2011;25(5):525-52.

53. Seitz T, Stalmann R, Dalila N, Chen J, Pojar S, Dos Santos Pereira JN, et al. Global genetic analyses reveal strong interethnic variability in the loss of activity of the organic cation transporter OCT1. Genome Med. 2015;7(1):56.

54. Tzvetkov MV, dos Santos Pereira JN, Meineke I, Saadatmand AR, Stingl JC, Brockmoller J. Morphine is a substrate of the organic cation transporter OCT1 and polymorphisms in OCT1 gene affect morphine pharmacokinetics after codeine administration. Biochem Pharmacol. 2013;86(5):666-78.

55. Venkatasubramanian R, Fukuda $T$, Niu J, Mizuno $T$, Chidambaran V, Vinks AA, et al. ABCC3 and OCT1 genotypes influence pharmacokinetics of morphine in children. Pharmacogenomics. 2014;15(10):1297-309.

56. Darbari DS, van Schaik RH, Capparelli EV, Rana S, McCarter R, van den Anker J. UGT2B7 promoter variant $-840 \mathrm{G}>$ A contributes to the variability in hepatic clearance of morphine in patients with sickle cell disease. Am J Hematol. 2008;83(3):200-2.

57. Matic M, Norman E, Rane A, Beck O, Andersson M, Elens L, et al. Effect of UGT2B7 -900G $>$ A $(-842 \mathrm{G}>\mathrm{A}$; rs7438135) on morphine glucuronidation in preterm newborns: results from a pilot cohort. Pharmacogenomics. 2014;15(12):1589-97.

58. van de Wetering K, Zelcer N, Kuil A, Feddema W, Hillebrand M, Vlaming ML, et al. Multidrug resistance proteins 2 and 3 provide alternative routes for hepatic excretion of morphine-glucuronides. Mol Pharmacol. 2007;72(2):387-94.

59. Sasaki T, Hirota T, Ryokai Y, Kobayashi D, Kimura M, Irie S, et al. Systematic screening of human $\mathrm{ABCC} 3$ polymorphisms and their effects on MRP3 expression and function. Drug Metab Pharmacokinet. 2011;26(4):374-86.

60. Lang T, Hitzl M, Burk O, Mornhinweg E, Keil A, Kerb R, et al. Genetic polymorphisms in the multidrug resistance-associated protein 3 (ABCC3, MRP3) gene and relationship to its mRNA and protein expression in human liver. Pharmacogenetics. 2004;14(3):155-64. 